Espacio, Tiempo y Forma, Serie II, Historia Antigua, t. 24, 2011, págs. 109-132

\title{
La poliorcética en el Imperio Neoasirio
}

\author{
Poliorcetic in Neo-assyrian Empire
}

Rubén SÁEZ AbaD*

\begin{abstract}
RESUMEN
ABSTRACT

Los Asirios contaron con las armas más avanzadas de su tiempo. Evolucionaron la guerra de sitio con la presencia de torres móviles, arietes y vehículos empujados a mano dotados de protecciones. Estos avanzados recursos permitieron la extensión de sus dominios por toda Mesopotamia.

Assyrians had the most advanced weapons of their time. They developed siege craft with mobile towers, battering rams and hand propelled vehicles with armor protection. These advanced resources allowed the extension of his domains for Mesopotamia

PALABRAS CLAVE:

Imperio Neoasirio, Poliorcetica, Till Barsip, Nimrud Assurnassirpal II, Tiglatpiuleser III

\section{KEYWORDS:}

Neo-Assyrian Empire, Poliorcetic, Till Barsip, Nimrud, Assurnassirpal II, Tiglatpiuleser III.
\end{abstract}

\section{INTRODUCCIÓN}

La guerra de asedio fue uno de los múltiples aspectos militares donde el ejército del Imperio Neoasirio alcanzó unas elevadas cotas de desarrollo, superando ampliamente a todos los estados vecinos con los que mantenía una abierta rivalidad. Precisamente, sería en esta superioridad, en cuanto a medios tecnológicos, donde se cimentaría buena parte del éxito de sus continuas campañas.

Aunque es probable que no fueran los inventores de muchos de los medios y recursos poliorcéticos de que hicieron gala, sí que consiguieron perfeccionar su comportamiento en combate y optimizar su empleo, hasta obtener de ellos un rendimiento sin parangón. Quizás, buena parte de este éxito radicara en la enorme movilización de medios materiales y humanos desarrollados durante sus operaciones militares, lo que sin duda permitió concentrar los recursos suficientes como para poder doblegar la resistencia de cualquier plaza fuerte.

\footnotetext{
* Doctor en Historia. Director de Trebuchet Park (Albarracín, Teruel). E-mail: correo@ @ubensaez.com
} 
Antes de entrar de lleno en las innovaciones obradas durante el periodo neoasirio, en lo referente a la guerra de asedio, para comprender su alcance es necesario tomar en consideración el contexto histórico en el que se produjeron. A partir del siglo IX a. C. comenzaron a proliferar las ciudades de cierta consideración en territorio mesopotámico. Simultáneamente al intenso proceso de urbanización obrado en la región, las nacientes metrópolis empezaron a adquirir un mayor peso como elementos vertebradores del espacio territorial.

En medio de este especial contexto es donde se produjo el surgimiento del Imperio Neoasirio como potencia regional. Ante su manifiesta incapacidad para proceder a la restauración del sistema productivo que había caracterizado a su precedente, el Imperio Medio Asirio, la única solución que le quedó a sus dirigentes fue la de recurrir a la realización de sucesivas campañas militares para el sostenimiento de la estructura del Estado.

Ya desde un temprano momento, las autoridades neoasirias se inclinaron por una política claramente belicista, realizando continuas operaciones militares destinadas a proporcionarles los recursos que resultaban vitales de cara a su supervivencia. Tan sólo garantizando el mantenimiento bajo su control de las rutas, que permitían el abastecimiento de los productos no existentes en territorio asirio, era posible sostener la economía productiva de los dominios imperiales en estado óptimo.

La base de cualquier política imperialista se cimenta sobre la conquista de nuevos territorios, siendo ésta una prioridad básica. Y, ahora que las ciudades habían aumentado, tanto en número como en tamaño, se hacía necesario disponer de unos recursos y medios técnicos acordes con las nuevas necesidades que venían imponiéndose.

A pesar de que se lograran amplias victorias sobre los contingentes enemigos en campo abierto, todos estos éxitos resultaban accesorios, en el caso de que no se consiguieran someter las urbes que jalonaban su territorio. Tomando en consideración que el control sobre el espacio rural, merced al incipiente proceso urbanizador, había dejado de ser garantía de sometimiento del rival, se hacía necesario un salto cualitativo en todo lo relacionado con la guerra de asedio.

Los dirigentes neoasirios dedicaron buena parte de sus esfuerzos al desarrollo tecnológico en este campo, de modo que sus unidades de infantería dispusieran de los equipos necesarios para conseguir doblegar la resistencia de cualquier ciudad, por muy bien amurallada que se encontrara. Gracias a la movilización de unos medios materiales y humanos sin parangón hasta ese momento, se produciría el surgimiento de la poliorcética (arte de atacar y defender las fortalezas) como ciencia (Sáez Abad, R., 2004: 42).

Las innovaciones obradas condujeron a que, desde el siglo IX a. C. los ataques a los recintos amurallados urbanos empezaran a multiplicarse de modo exponencial, especialmente a lo largo de todo el territorio mesopotámico. Y, en medio de este excepcional marco regional, el Imperio Neoasirio sería la potencia dominante 
durante tres siglos, marcando sus innovaciones profundamente el devenir del mundo grecorromano posterior.

\section{TÉCNICAS DE ASEDIO}

Tras una primera aproximación a la importancia que adquirieron las ciudades durante el Imperio Neoasirio, como elementos claves dentro de la estrategia militar, a continuación se hace necesario analizar las diferentes técnicas empleadas para conseguir su rendición. En relación a este último punto, existía la posibilidad de utilizar medios pacíficos o violentos para conseguir la finalidad perseguida. Tanto en un caso como en otro, eran muchas las opciones con que contaban los dirigentes militares para lograr un mismo objetivo: la captura del recinto amurallado enemigo.

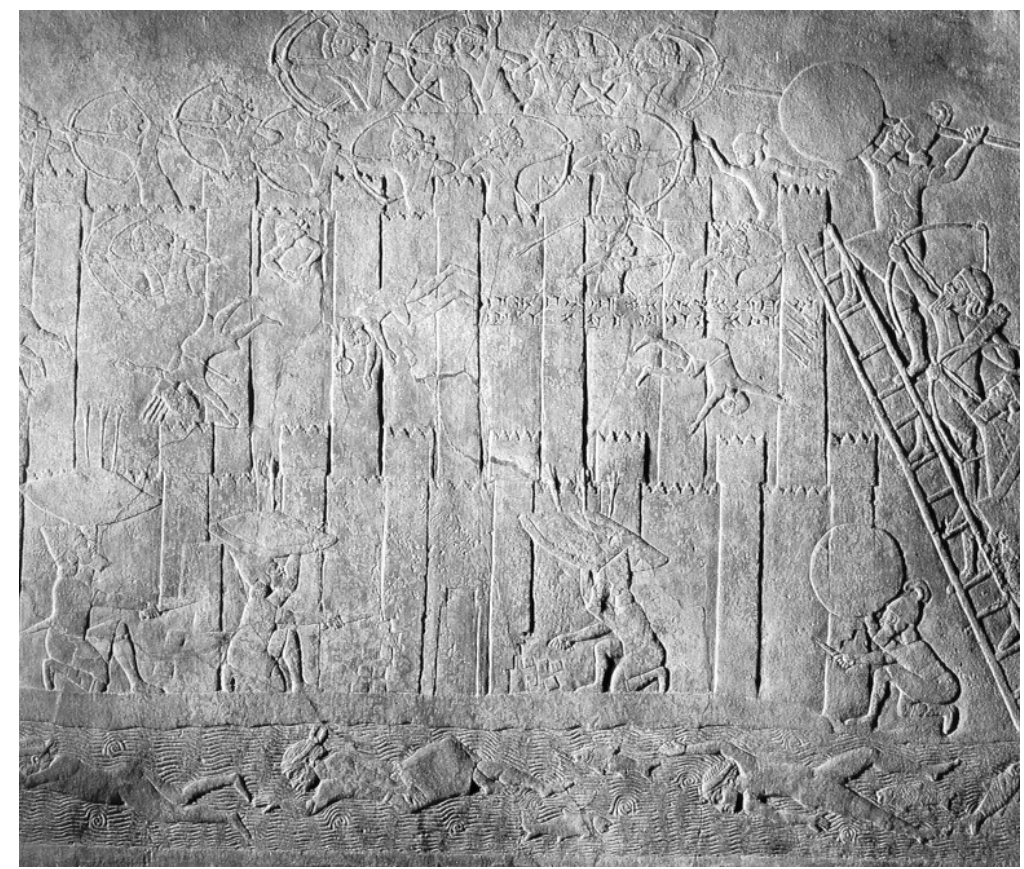

Fig. 1. El ejército de Assurbanipal asaltando la ciudad de Hamanu.

En su ataque emplean escalas, mientras otros soldados tratan de minar la base de las murallas. Relieves del Palacio Norte de Nínive, British Museum, Londres.

\subsection{Captura por medio de gestiones diplomáticas}

Antes de profundizar en las técnicas que usaban la fuerza bruta para lograr la capitulación de cualquier plaza fuerte, existía la posibilidad de recurrir a una serie de medios de carácter no violento. La primera de las estrategias a emplear era de- 
jar que la diplomacia fuera la encargada de hablar, buscando una salida negociada al conflicto que impidiera se llegara finalmente al enfrentamiento armado.

En el caso de que las gestiones terminaran por dar sus frutos, todo eran ventajas para el ejército atacante. Por un lado, se evitaba un gasto económico innecesario, pues hay que tener en cuenta que las operaciones de asedio solían demorarse mucho en el tiempo, lo que suponía un desembolso de consideración para las arcas imperiales. Al mismo tiempo, también desaparecía cualquier coste humano, un factor que no podía ser considerado menor a la hora de abordar cualquier campaña de larga duración. Las sucesivas bajas conseguían provocar, en algunas ocasiones, incluso la detención de las operaciones militares. Por lo tanto, pleno de ventajas y escasos inconvenientes cuando se optaba por la elección de la diplomacia como vía.

No obstante, conseguir que una ciudad aceptara rendirse sin necesidad de combatir, a menudo resultaba una tarea muy complicada. Ninguna ciudad, con una mínima opción de resistir un asedio, se prestaba a aceptar la conquista y sometimiento de buen grado. En este último supuesto, los atacantes tenían la opción de recurrir a una serie de iniciativas, todas ellas destinadas a minar la moral de los contingentes defensores. Hay que tener en cuenta que la guerra es un estado de ánimo y cualquier pequeña victoria anímica podía decantar a los indecisos hacia la capitulación.

En ocasiones puntuales, la sola reputación de un dirigente militar era más que suficiente para que desaparecieran las últimas dudas en relación a cuál debía ser la decisión a tomar. Tan sólo haciendo acto de presencia ante las murallas enemigas al frente de sus fuerzas militares, su aparición podía forzar la rendición de una plaza fortificada. En el peor de los casos, se conseguía presionar a que sus autoridades, al menos aceptaran la apertura de negociaciones.

Normalmente, a la presentación del dirigente atacante le solía acompañar la realización de un alarde de fuerza, procediéndose al despliegue de todo el ejército ante las murallas enemigas. Este gesto, de profundo simbolismo, tenía como objeto persuadir al enemigo para demostrarle de lo inútil de prolongar su resistencia, poniendo todas sus cartas sobre la mesa. Sin embargo, este recurso tan sólo era útil cuando la disparidad entre el número de atacantes y defensores podía ser más que suficiente para inclinar la balanza.

Para tratar de romper este equilibrio de fuerzas, los dirigentes neoasirios practicaron un aspecto de la guerra tan de actualidad, como es la "guerra psicológica». Para ello, impusieron una especie de reinado del terror sobre los pueblos circundantes, por medio de la imposición de brutales castigos sobre los habitantes de toda ciudad que osara presentar el menor gesto de resistencia o de rebeldía frente al poder establecido.

A lo largo de la iconografía neoasiria, y especialmente en las imágenes procedentes de Till Barsip y de Nimrud, es posible observar numerosas escenas de decapitaciones masivas de enemigos tras ser derrotados en batalla. Estas repre- 
sentaciones son especialmente abundantes en la sala del trono de Assurnassirpal II, en un claro caso de propaganda política. De este modo, les mostraban a los embajadores de las potencias vecinas lo que les esperaba en el caso de que osaran desafiar su poder.

A las decapitaciones se unían otros brutales métodos de castigo infligidos sobre los enemigos derrotados en batalla. El empalamiento, el desollamiento o el desmembramiento, eran prácticas bastante habituales en el mundo neoasirio, a tenor del elevado número de ocasiones en las que aparecen representados o se mencionan en los textos contemporáneos. La finalidad de estas medidas, extremadamente brutales a nuestros ojos, era claramente moralizante.

Desde Tiglatpileser III quedó establecido un nuevo método de castigo para aquellos pueblos y ciudades que fueran sometidos de forma íntegra. Consistía en la deportación en masa de sus habitantes, dispersándolos a lo largo del resto de dominios imperiales. El alcance de esta medida llegaba hasta el punto de que, el grupo humano afectado por ella, perdía cualquier atisbo de personalidad colectiva, haciendo desaparecer todo vínculo con sus raíces. El siguiente relato de una serie de castigos multitudinarios sirve muy bien para ilustrar lo afirmado anteriormente:

«En el enfrentamiento y el conflicto yo sometí y conquiste la ciudad. Hice caer a 3.000 de sus hombres con la espada. Yo me llevé los prisioneros, las posesiones y ganado de ellos. Quemé a varios cautivos. Capture muchas tropas vivas, les corte los brazos y las manos... arrasé, destruí, incendié, y consumí la ciudad.»

Amparados en el miedo, los dirigentes militares neoasirios confiaban en que la mayor parte de las ciudades optara por rendirse sin combatir, tan pronto se presentara el ejército ante sus muros. $\mathrm{Y}$, lo cierto es que estos expeditivos métodos cumplían su objetivo a la perfección, permitiendo la conquista de amplios territorios sin necesidad de lucha. De este modo se evitaba un elevado coste, en lo que a pérdidas humanas se refiere, al mismo tiempo que se ahorraba tiempo y dinero.

No obstante, el empleo de esta extrema violencia también corría el riesgo de volverse en contra del atacante, pues el miedo podía llevar a que las poblaciones atacadas prolongaran la resistencia hasta sus últimas consecuencias. El temor a ser objeto de los mayores suplicios capaces de soportar el ser humano, exacerbaba los ánimos de los habitantes de las poblaciones, inclinándoles a luchar hasta la muerte. La falta de esperanza se convertía, de este modo, en la más poderosa de las armas.

La escasez de posibilidades de supervivencia, a menudo conduce a los hombres a luchar hasta la extenuación, siendo capaces de gestos de valor muy por encima de lo habitual en condiciones de normalidad. Por lo tanto, el comportamiento extremadamente violento con el enemigo se convertía en un arma de doble filo, que podía generar más problemas que soluciones.

Otro aspecto nada desdeñable, dentro de los recursos poliorcéticos carentes de violencia, y que a menudo no se suele tomar en consideración, era la posibili- 
dad de sobornar al enemigo. El monarca Filipo II de Macedonia siempre se inclinaba por «ver si el oro era capaz de hacer caer las murallas antes que la fuerza de las armas». Aunque son pocas las evidencias que se tienen a este respecto en el mundo neoasirio, es bastante probable que alguna de las plazas conquistadas durante su larga carrera militar lo hiciera por este método. Gracias a su empleo, de nuevo se lograban los objetivos con un menor coste material y humano.

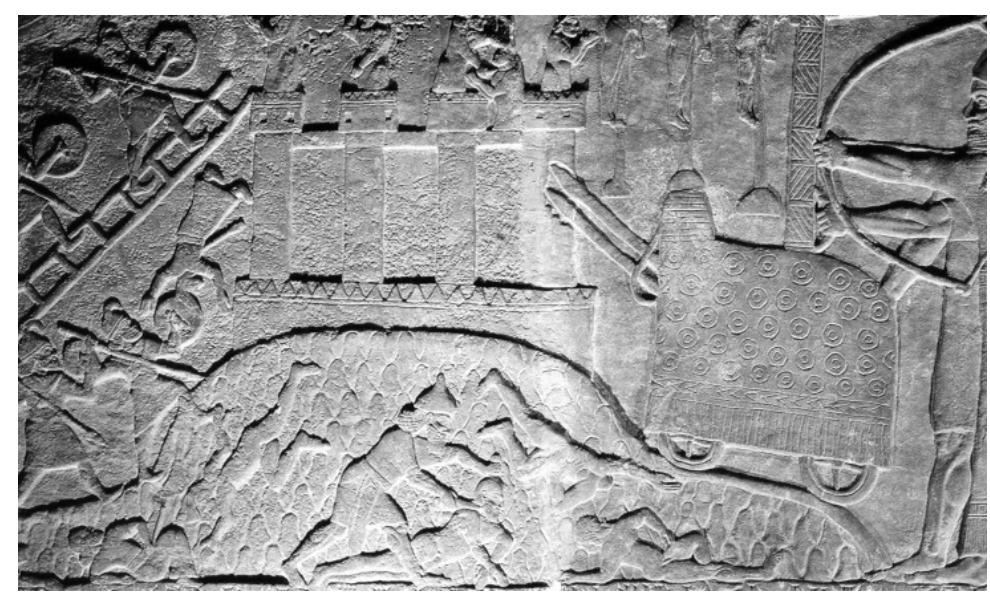

Fig. 2. Ataque sobre una plaza fuerte por medio de escalas y una torre de asedio equipada con un ariete doble. Relieves de Tiglatpileser III. Palacio Central de Nimrud, British Museum, Londres.

\subsection{Asalto por sorpresa}

En el caso de que la vía diplomática fracasara, algo que solía ser bastante habitual, se hacía necesario hacer un replanteamiento de la situación y optar por la vía armada como solución. En la mayor parte de las ocasiones, y como primera medida, los atacantes trataban de forzar las murallas por medio de un intento de asalto a viva fuerza. Es necesario señalar que esta opción tenía, tras la realización del alarde de fuerzas atacantes ante los muros, unas escasas posibilidades de éxito. Desaparecido el factor sorpresa, la probabilidad de victoria se había esfumado.

A pesar de no lograrse la captura de las murallas por medio de esta tentativa, la acción se convertía en un buen termómetro para baremar el estado de ánimo de la guarnición, así como sus capacidades combativas. La toma de una ciudad amurallada o de una fortaleza al asalto era un caso absolutamente excepcional, constituyendo una técnica minoritaria en relación al resto de recursos en que podían apoyarse los ejércitos neoasirios.

El empleo de esta estrategia de ataque, sin el apoyo de medios pesados de asedio adicionales, tan sólo gozaba de cierto sentido en el caso de que la des- 
proporción entre atacantes y defensores fuera muy acusada. Cuando se recurría al asalto por sorpresa en superioridad numérica, los atacantes siempre solían lanzar su ofensiva a lo largo de un amplio trecho del recinto amurallado, de modo que los defensores se vieran forzados a dividir sus fuerzas. Al serles imposible concentrar sus escasos recursos humanos en un único sector del trazado defensivo, las operaciones de conquista se veían facilitadas.

El empleo de la técnica de asalto por sorpresa ofrecía muchas opciones diferentes, pudiendo combinarse con otros recursos ajenos. Para aumentar su porcentaje de éxito era posible contar con la ayuda de traidores en el interior de los muros, de tal modo que facilitaran la captura del recinto amurallado en cuestión. El grado de participación de los conspiradores variaba, pudiendo ir desde facilitar el santo y seña para la superación de las puertas por parte de agentes enemigos, hasta la apertura de una brecha practicable en los muros para el acceso de los asaltantes.

Dejando de lado la presencia de agentes infiltrados, capaces de crear una quinta columna en el interior de la ciudad atacada, la captura de una plaza fuerte se podía lograr aprovechando multitud de factores, especialmente los climatológicos. La caída de intensos aguaceros o la aparición de una densa niebla, se convertían en elementos capaces de ocultar cualquier movimiento asaltante. En medio de estas peculiares circunstancias la defensa se tornaba muy complicada, limitando notablemente las capacidades de intervención de los contingentes defensores.

La oscuridad nocturna también ayudaba a proporcionar el marco idóneo para la realización de los ataques por sorpresa, haciendo que cualquier movimiento pasara desapercibido a la guarnición. Una vez dentro de los muros, el escaso número de intrusos que había conseguido superar las murallas, se dedicaba a abatir a los vigías y centinelas para facilitar la entrada del resto del ejército, con lo cual se consumaba la captura del recinto.

Para la realización de estas operaciones de asalto por sorpresa se empleaban unidades militares dotadas de un elevado grado de especialización. En su misión empleaban recursos y medios técnicos muy limitados, como escalas de cuerda o soga, escaleras de madera, garfios y piquetas. Cualquier elemento que facilitara la escalada era válido para lograr la superación de los muros. Uno de los motivos más representados en los relieves asirios es el de diferentes soldados ascendiendo a través de escaleras. Aunque no es posible conocer si esas imágenes aluden a asaltos en operaciones de asedio reglamentadas y planificadas, o a maniobras por sorpresa, es lógico pensar que también se ejecutaran estos últimos ataques de bajo perfil.

Sin embargo, la elección de esta técnica planteaba una serie de dificultades insalvables. Si se toma en consideración el exiguo número de soldados que integraban los cuerpos de operaciones especiales encargados de ejecutarlas, tan sólo era posible conseguir el éxito contra fortalezas de pequeñas dimensiones y guarnecidas por un escaso número de tropas. Frente a ciudades amuralladas de 
cierta consideración, defendidas por un amplio contingente militar, eran remotas las esperanzas de éxito.

Aunque se lograra una victoria inicial, la conquista sólo podía consumarse gracias a la intervención de un ejército de considerables dimensiones. Este ejército permanecía oculto a la espera de acontecimientos dentro de la ciudad, aproximándose tan sólo cuando la resistencia inicial había quedado neutralizada. No obstante, a causa de sus dimensiones, era extremadamente difícil que su presencia pasara inadvertida por mucho tiempo en territorio enemigo.

Tan pronto se tenían noticias dentro de cualquier ciudad, posible objetivo militar, de una presencia hostil en sus inmediaciones, se extremaban las medidas defensivas. Ante el temor a ser objeto de ataque, se incrementaban numéricamente los contingentes desplegados en lo alto de los muros, extremándose la vigilancia hasta del más mínimo movimiento que resultara sospechoso.

Esta serie de particulares condicionamientos de índole táctica, conducían a que la estrategia de asalto por sorpresa fuera desechada en la mayor parte de las ocasiones. En el caso de que la operación no estuviera bien planificada, también se corría el riesgo de que todo el cuerpo participante en la operación quedara exterminado. Al tratarse de unidades escogidas, su pérdida se podía convertir en un pesado lastre, difícil de sustituir a corto plazo en campaña.

\subsection{Bloqueo}

Una vez analizadas las escasas probabilidades de éxito que revestía el empleo de la técnica de asalto por sorpresa, pasaremos a revisar las tácticas de asedio necesitadas de un mayor grado de elaboración y que se basaban en una serie de principios poliorcéticos más o menos estandarizados. En este sentido, las estrategias para apoderarse de una ciudad eran básicamente dos, amén de sus respectivas variantes: rendirla por hambre o asaltarla y capturarla por la fuerza de las armas.

La primera de las estrategias consistía en bloquear la ciudad con respecto al exterior, construyendo para ello una línea de cerco alrededor de todo su perímetro amurallado. Por medio de este despliegue se buscaba aislar al enemigo con respecto al entorno circundante, de modo que se impidiera su abastecimiento de víveres o tropas. Esta opción presentaba diferencias en función del grado de aislamiento conseguido: parcial y total.

En el bloqueo parcial, las maniobras ofensivas se limitaban a construir campamentos de sitio frente a las puertas principales de la ciudad, de tal manera que se perjudicaban las comunicaciones de la ciudad, aunque no quedaban totalmente interrumpidas. Por el contrario, en el total sí que se buscaba explícitamente la circunvalación, de modo que no quedara ningún resquicio para que los habitantes pudieran moverse. 
En el caso de inclinarse finalmente por esta opción, los dirigentes atacantes tan sólo se tenían que limitar a protegerse de las salidas efectuadas desde el interior de la ciudad atacada o a la posibilidad de que llegara un ejército de socorro que obligara a los atacantes a levantar el asedio. La clave del asedio residía en conseguir que la línea de bloqueo alcanzara una impermeabilidad completa, pues en caso contrario el sitio podía prolongarse indefinidamente.

Las ventajas del empleo de la técnica de bloqueo residían en el reducido coste que suponía, en lo que a pérdidas humanas se refiere. No obstante, como contraposición, también implicaba mantener inmovilizados durante un amplio periodo de tiempo considerables contingentes armados, lo que redundaba también en un mayor coste económico.

Al mismo tiempo, el empleo del bloqueo necesitaba de un elevado número de tropas entre las filas atacantes, de tal manera que quedara asegurado el perímetro amurallado en toda su extensión. Cualquier mínimo hueco que quedara sin custodia podía dar al traste con la operación, por lo que se requería de una concentración de recursos humanos a la altura de muy pocos imperios. En ese sentido, la capacidad de movilización de tropas dentro del Imperio Neoasirio, con ejércitos de maniobra por encima de los 50.000 soldados, hacía que el número no fuera en ningún caso un problema.

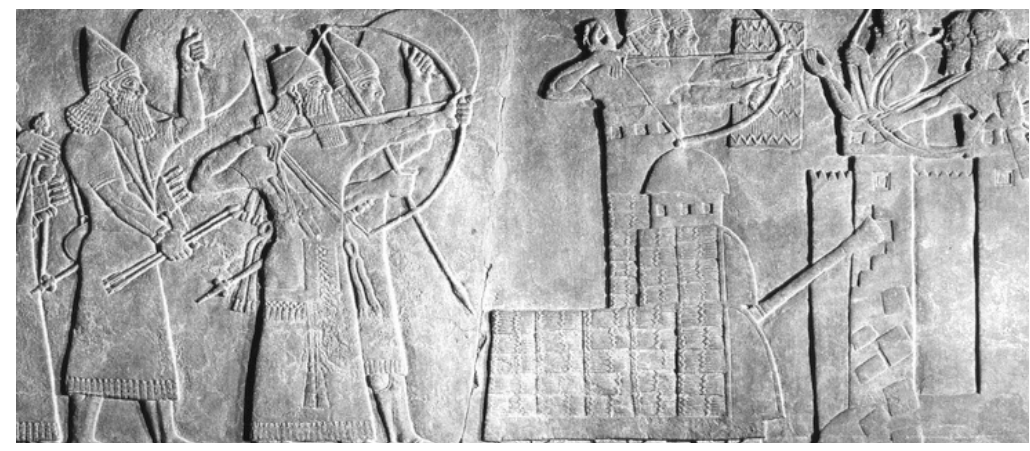

Fig. 3. Escena de ataque sobre una plaza fuerte con una torre de asedio pesada, apoyada por el fuego de diferentes unidades de arqueros. Relieves del Palacio Noroeste de Assurnasirpal II en Nimrud. British Museum, Londres.

Sin embargo, y a pesar de la enorme disposición de tropas, se hacía necesario conseguir un equilibrio entre los contingentes disponibles y los necesarios. Como ya se ha señalado anteriormente, el sostenimiento de las fuerzas de sitio requería de considerables gastos en recursos, especialmente alimento para los soldados y los animales, por lo que se evitaba a toda costa el empleo de más hombres de los considerados estrictamente necesarios. Cualquier fuerza adicional también suponía una inversión extra, de modo que se trataba de minimizar el impacto económico en la medida de lo posible. 
Siempre que se recurría al empleo de la técnica de bloqueo, la logística pasaba a ocupar un papel clave en la estrategia militar, pues era vital mantener la capacidad combativa de la tropa, y eso sólo se lograba cuando los soldados se encontraban bien alimentados y abastecidos. Si se descuidaba este aspecto, la falta de recursos podía forzar a los sitiadores a levantar el asedio, haciendo fracasar el trabajo de varios meses o incluso años.

\subsection{Bloqueo activo}

Tomando en consideración el elevado coste económico derivado del empleo de la estrategia de bloqueo, eran muchos los dirigentes militares neoasirios que se inclinaban por tratar de reducir la duración de los asedios en la medida de lo posible. Cada jornada adicional que se prolongaba un sitio se incrementaba el gasto, por lo que se hizo necesaria la búsqueda de nuevos recursos poliorcéticos capaces de acortar los tiempos.

Ahí es donde entraban en juego las máquinas de asedio, que contribuían a abaratar los costes de las operaciones militares, al permitir la captura de las plazas enemigas en un menor espacio de tiempo.

La principal dificultad para conquistar una ciudad fortificada era superar las murallas, único obstáculo que impedía la entrada desde el exterior. En este caso, las opciones sólo eran tres:

- Superar los muros por su parte inferior por medio del minado.

- Superar los muros por su parte superior con escalas o torres de asedio.

- Superar los muros, abriendo una brecha a través de ellos con la ayuda de arietes.

\section{MÁQUINAS DE ASEDIO Y RECURSOS POLIORCÉTICOS}

\subsection{Superación de las murallas por su parte inferior: el minado}

La forma de superar las murallas por su parte inferior consistía en la apertura de brechas gracias al trabajo de minado. Este recurso resultaba muy práctico, merced sobre todo al material constructivo empleado en territorio mesopotámico a la hora de levantar sus recintos amurallados: el adobe. Las peculiares características de este material lo convertían en especialmente vulnerable frente al empleo de la guerra de minas. Así pues, con poco esfuerzo se podían conseguir grandes réditos.

Por otro lado, tampoco obligaba a comprometer un elevado número de tropas en la ejecución, por lo que su coste humano nunca resultaba excesivo. En varios de los relieves neoasirios se aprecian grupos de soldados operando a los pies de 
la muralla y descarnado su obra constructiva. Para la realización de esta labor emplean una especie de pequeños cuchillos, por medio de los cuales van arrancando los adobes uno tras otro. Se aprecia cómo ya han retirado algunas piezas y empieza a abrirse brecha en las defensas.

Los soldados únicamente van protegidos por medio de un escudo circular, debajo del cual se esconden para poder trabajar a cubierto. El escudo lo portan en la mano izquierda, mientras que con la derecha manejan el cuchillo encargado de facilitar las operaciones de ruptura. Como curiosidad, es necesario señalar que los escudos bajo los que se protegen los soldados llevan clavadas varias flechas, lo que revela muy a las claras el considerable riesgo que corrían los soldados encargados de esta peligrosa misión.

En uno de los relieves es posible apreciar la presencia de un escudo de grandes dimensiones, mucho más alto que el soldado que debe proteger. Tiene forma curvada y está dotado de techo, de modo que el zapador pudiera trabajar a los pies de los muros sin resultar alcanzado por las flechas. No obstante, es imposible distinguir la forma en la que se anclaba al suelo o se manejaba, quedando tan sólo como un elemento anecdótico de este tipo de protecciones (Bentley Kern, P., 1999: 51).

Si bien, en Grecia el grado de exposición de los soldados encargados del minado al fuego enemigo era escaso, no así en el mundo neoasirio. Tal y como se aprecia en los relieves, quedaban expuestos a que los defensores pudieran arrojarles desde lo alto todo tipo de proyectiles pesados. Sus livianas protecciones en forma de escudo, no podrían haber aguantado, en ninguno de los casos, el impacto de proyectiles pesados, corriendo un grave peligro.

No obstante, en muchas de las ocasiones se aprecia la combinación del trabajo de minado con el empleo de otras técnicas de forma simultánea, como por ejemplo los intentos de asalto por medio de escalas. De este modo, se obligaba a los contingentes defensores a dividir sus fuerzas, aliviando a las unidades de minado de buena parte del riesgo que corrían.

Las tareas de excavación podían tener dos fines muy diferentes, pero ambos con la misma finalidad: la ruptura de la defensa. Las minas se empleaban para excavar un túnel, a través del que los asaltantes penetraran en el interior de la plaza atacada. Tras rebasar las murallas, los invasores esperaban el momento idóneo para finalizar el trabajo. Éste podía llegar con la noche o ser simultaneado con un ataque de distracción contra los muros. La prioridad de la unidad de asalto consistía en romper los cerrojos de alguna de las puertas y facilitar la entrada del resto del ejército al interior. En los relieves del palacio de Nimrud se observa a varios soldados trabajando en operaciones de minado, mientras al mismo tiempo las torres de asedio baten las murallas con sus arietes pesados.

Las obras de minado también tenían como objeto provocar la caída de un lienzo amurallado. Para ello, era necesario avanzar hasta los cimientos de las fortificaciones y, una vez alcanzados, retirar las piedras que formaban parte de la línea 
de cimentación hasta lograr que terminaran por venirse abajo. De este modo, se permitía la entrada de los soldados asaltantes a pie llano, una vez la brecha llegara a ser practicable.

A pesar de la aparición del trabajo de minado en los relieves asirios, su escasez con respecto a la presencia de otros medios de asedio, como por ejemplo las torres móviles, nos lleva a pensar que su uso sería minoritario. El elevado número de pérdidas sufridas entre sus integrantes, eso sí nunca muy numerosos, sin duda alguna influiría en su uso minoritario. También su lentitud, con respecto a otros recursos, podía influir en el hecho de que fuera desechado. De todos modos, no dejaba de ser otro de los muchos medios disponibles con que los dirigentes militares contaban a la hora de abordar un asedio.

\subsection{Superación de las murallas por su parte superior: escalas y torres}

\subsubsection{Las escalas}

La forma más habitual, para tratar de superar las murallas por su parte superior, consistía en el empleo de escalas y escaleras. Sus ejemplares más simples estaban elaborados con cuerda y madera, adoptando un diseño semejante al que presentan las escaleras actuales. Eran muy útiles para la realización de ataques por sorpresa u operaciones combinadas con otros medios y recursos.

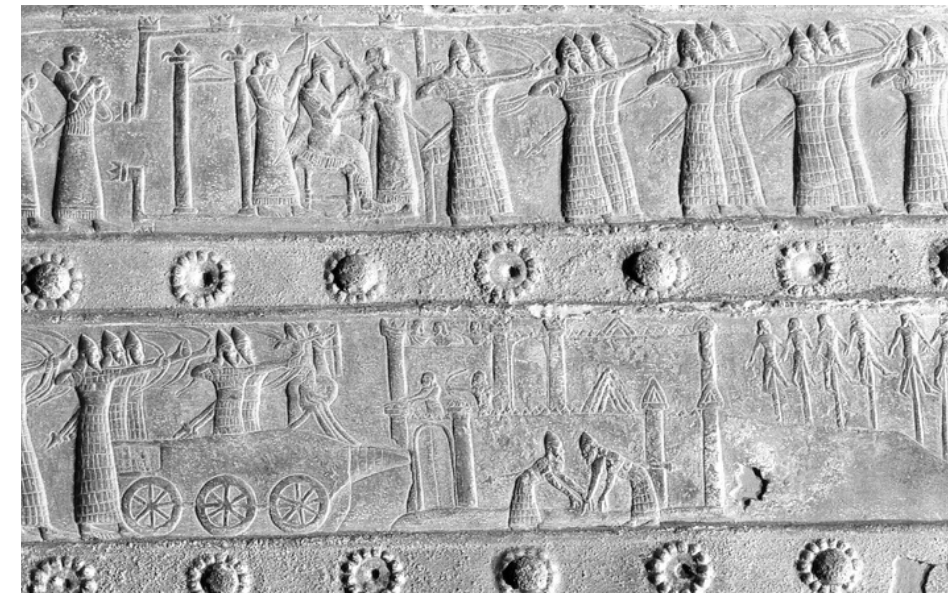

Fig. 4. Ariete pesado batiendo la puerta de una plaza fuerte durante la campaña de Salmanasar III en Armenia. Puerta de Balawat. British Museum, Londres.

Sin embargo, el empleo de las escaleras planteaba una serie de problemas, que no pueden ser considerados menores. Hay que tomar en consideración que los soldados que subían a través de ellas quedaban excesivamente ex- 
puestos a los disparos efectuados por parte de los defensores. También se corría el riesgo de que las escalas pudieran ser volcadas por las unidades desplegadas en lo alto de los muros, abatiendo a todos los soldados que subieran de forma simultánea.

En este sentido, un reducido número de defensores sería más que suficiente, sin el concurso de otros recursos poliorcéticos, para mantener a raya a ejércitos por muy numerosos que fueran. De ahí que, siempre que aparezcan las escalas en los relieves neoasirios, lo hagan en combinación con otros medios, como el minado o el empleo sistemático de torres de asedio. Sólo de ese modo se podría extraer de las escalas su máximo rendimiento, minimizando las pérdidas sufridas.

De nuevo, volvemos a apreciar la necesidad de obligar al enemigo a dividir sus fuerzas a lo largo de todo el perímetro amurallado, facilitando que las unidades más expuestas (zapadores o escaladores) tuvieran alguna oportunidad de éxito. La combinación de medios y técnicas de asedio es una constante que se aprecia a lo largo de la iconografía, empleo que permite corroborar la complejidad de las técnicas poliorcéticas neoasirias.

\subsubsection{Las torres de asedio}

A tenor de los acusados problemas que venían arrastrando las escaleras y escalas de asalto, los dirigentes militares optaron mayoritariamente por el empleo de otras máquinas de mayores dimensiones, como eran las torres de asedio. La preeminencia, en cuanto a su uso, mayoritariamente respondía a la necesidad de minimizar las pérdidas humanas durante las operaciones de ataque.

Se desconoce exactamente cuando se produjo la aparición de las primeras torres de asedio en territorio mesopotámico. No obstante, los archivos de Mari, datados a principios del segundo milenio a. C., ayudan a proporcionarnos unas primeras pautas para situar cronológicamente el origen de estos pesados ingenios de sitio. En dichos registros aparecen referencias al empleo de las primeras torres móviles dotadas de arietes en su base (dimtum).

Como curiosidad, es necesario señalar que en dichos textos también se alude a la erección de las rampas de asedio necesarias para facilitar el desplazamiento de las máquinas hasta la base de los muros enemigos. La precisión de los documentos llega hasta el punto de que, incluso proporcionan las dimensiones de los levantamientos de tierra requeridos para poder disponer las torres en posición ventajosa sobre las murallas. Así, se especifica que debían alcanzar los 240 metros de longitud, en el caso de que se quisiera salvar un desnivel de 22 metros.

A tenor de estos escasos datos disponibles, resulta imposible conocer el aspecto que tendrían estas primitivas torres de asedio. Sin embargo, tendemos a pensar que guardarían ciertas similitudes con los ingenios representados varios siglos después en los relieves del Imperio Neoasirio. 
Si prescindimos de la información existente en el archivo de Mari, la primera representación explícita de una torre de asedio la encontramos en los relieves del Palacio de Assurnasirpal II de Nimrud, datado en la primera mitad del siglo IX a. C. Los ingenios que se muestran en estas imágenes son una especie de torres, de carácter móvil, que presentan un aspecto bastante macizo en cuanto a su construcción.

La calidad de estos grabados es tal, que pueden ser considerados sin lugar a dudas, la capilla Sixtina del arte poliorcético durante la Antigüedad. Ni siquiera en el mundo grecorromano es posible encontrar una serie de relieves con tal calidad y en la que se aprecie con tanto detalle el marco de actuación en el que operaban los diferentes medios de asedio disponibles.

Las variedades tipológicas de torres presentes en la iconografía son muchas, aunque todas ellas guardan ciertas similitudes entre sí. Por un lado, encontramos torres de planta rectangular, dotadas de una torreta cuadrada en su parte delantera, elemento que terminaba coronado por una estructura circular. Este último componente guardaría tipológicamente ciertas similitudes con las garitas empleadas en Época Moderna para la defensa de los ángulos de las fortificaciones. Y, en cierto modo, su función era la misma: poder disponer unidades de arqueros en su interior, funcionando a la manera de las torretas de los modernos tanques.

Otro diseño presente en los relieves guarda muchas similitudes con la tipología más habitual empleada en el mundo grecorromano varios siglos después. Consistía simplemente en una estructura vertical de madera desplazada por medio de ruedas y que quedaría dividida en diferentes pisos. A cada uno de ellos se accedería a través de diferentes escaleras dispuestas en el interior o en su parte trasera.

La división en pisos es una constante en las diferentes torres, oscilando su número en función de los diferentes modelos. Siempre, el primero de ellos y más cercano al suelo, estaba equipado con un ariete manejado por soldados de infantería, que permanecían resguardados en el interior de la máquina. Las alturas siguientes cumplirían las funciones de plataformas de disparo para unidades de arqueros, resultando especialmente útiles las que se hallaban al mismo nivel que la muralla a batir o en posición dominante sobre ella.

En ninguno de los relieves neoasirios se aprecia la presencia de puentes abatibles de desembarco dentro de las torres. Estos elementos estaban destinados a dejarse caer sobre las murallas, para que a través de ellos pudieran cruzar unidades de infantería y apoderarse de los coronamientos de la muralla. La ausencia de los puentes haría que estas máquinas perdieran buena parte de sus capacidades ofensivas. Lo que sí debía estar presente en el último de los pisos es algún depósito de agua, destinado a combatir las llamas en el caso de que prendieran sobre su estructura.

Ya respondieran a una tipología o a otra, a la hora de construir cualquier torre era necesario partir de un chasis o estructura de madera inicial, destinada a pro- 
porcionar la configuración definitiva a la máquina. Posteriormente, todo el conjunto se recubría de escudos en su cara exterior, de modo que se viera incrementado el grado de protección de sus ocupantes.

Todas las torres móviles representadas en los relieves están provistas de un ariete en su parte frontal. En ocasiones, es posible apreciar una doble viga en lugar del modelo sencillo, lo cual multiplicaría sus capacidades ofensivas durante las operaciones de expugnación. Al igual que encontramos variedad de torres de asedio, las cabezas de estos arietes también son múltiples. Así, es posible observar cabezas que acaban en una especie de cobertura circular metálica a modo de paleta. Sin duda alguna, su uso tenía como objeto impedir que la viga de impacto se agrietara a causa de los repetidos choques contra los muros.

No obstante, el modelo más habitual de cabeza en los arietes es la que termina en una punta de lanza. Este tipo de diseño sería especialmente útil contra las fortificaciones elaboradas a base de adobes. En combate, la pieza metálica se clavaría entre las diferentes hiladas de la construcción, terminando por descarnar la muralla hasta facilitar la apertura de una brecha practicable para el asalto de las unidades de infantería.

El ariete sería accionado desde el interior de la torre por medio de una especie de movimiento de péndulo. La viga quedaba fijada al techo del primer piso por medio de un sistema de cuerdas, al igual que sucedería en todos los modelos empleados con posterioridad. Operando desde la parte trasera de la máquina, el ariete trabajaría de forma repuntada, pues una constante que se aprecia en todos los relieves es que la cabeza trabaja bastante levantada en relación con el cuerpo de la máquina. De este modo, se reducía considerablemente la capacidad de impacto de la cabeza, pues su grado óptimo de operación era trabajar en la horizontal (Sáez Abad, R., 2004: 76).

A partir del reinado de Tiglatpileser III empieza a apreciarse un cambio en la configuración externa de las máquinas, apareciendo como ingenios mucho más ligeros y manejables. De cara a evitar que su estructura pudiera prender fuego, comenzaron a cubrirse todas sus caras con pieles sin curtir. Este descubrimiento pasó a otorgar a las máquinas una protección adicional frente a los componentes incendiarios. Las innovaciones obradas son perfectamente apreciables en los relieves de Senaquerib, en los cuales el grado de detalle alcanza hasta tal punto que se aprecian las fijaciones de las pieles a la estructura.

Otro aspecto difícil de evaluar, a tenor de la falta de escala y perspectiva presente en los relieves neoasirios, es el tamaño que tendrían estas máquinas. Tomando en consideración las dimensiones de los recintos amurallados conservados del periodo, y teniendo en cuenta que era necesaria su superación en altura, se estima que se situarían entre los 4 y los 6 metros de longitud, además de entre 5 y 6 metros de altura. Sin embargo, hay que tener en cuenta que podrían emplearse torres de asedio de mayores dimensiones en momentos puntuales, pues siempre venían condicionadas sus medidas por las características peculiares de la muralla a combatir. 
Estas inmensas máquinas de asedio se hacían avanzar gracias a la fuerza muscular de sus ocupantes, desplazándose por medio de ruedas, cuyo número variaría en las diferentes torres. Así, encontramos diseños con cuatro y seis ruedas, dispuestas respectivamente en dos y tres ejes. Estas variantes nos conducen a considerar la existencia de modelos de máquinas ligeros y pesados, utilizados indistintamente según las necesidades. No obstante, parece apreciarse un mayor número de ruedas en los modelos más antiguos, reduciéndose a medida que fueron evolucionando.

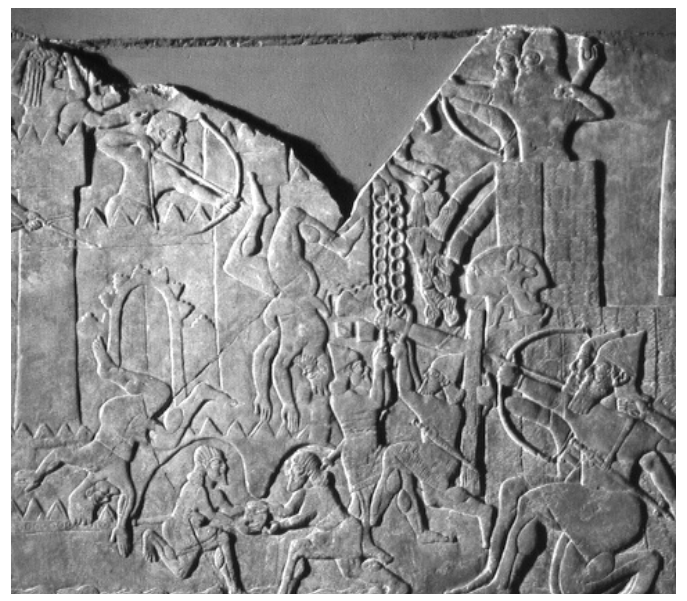

Fig. 5. Torre de asedio batiendo una muralla con su ariete. Obsérvese cómo los defensores tratan de levantar la cabeza del arma, mientras los atacantes tratan de devolverla a su posición original. Palacio Noroeste de Nimrud. British Museum, Londres.

Los ejemplares representados en los relieves presentan radios en número indeterminado, pudiendo oscilar entre los cuatro y los ocho. La presencia de este tipo de ruedas lleva a pensar que el peso de las torres no sería muy elevado, pues en caso contrario se hubiera optado por construirlas de forma maciza. Sus similitudes con los diseños presentes en los carros resultan evidentes.

En combate, las torres siempre operaban del mismo modo. Desde la distancia funcionaban como una especie de muralla móvil, que se podía acercar y alejar de las murallas de la ciudad que eran fijas. Esta movilidad otorgaba una enorme versatilidad a la máquina, marcando la distancia de fuego a la que el atacante condicionaba que se desarrollara el combate. La facilidad, en cuanto a su desplazamiento, se convertía en la principal ventaja que poseían los atacantes sobre sus contrincantes, aunque es necesario señalar que la construcción de las rampas limitaba mucho su ámbito de actuación. Y, una vez a los pies de la muralla, comenzaban a operar los arietes del piso inferior. De este modo, las torres combinaban el ataque desde lejos con la operatividad desde cerca, lo que proporcionaba una enorme gama de opciones a sus ocupantes. 


\subsection{Superación de las murallas abriendo una brecha a través de ellas}

El principal recurso empleado para la apertura de brechas en los recintos amurallados consistía en la utilización de arietes. Si las dudas acerca de la aparición de las primeras torres de asedio son numerosas, en el caso de los arietes éstas todavía se ven incrementadas.

Hay que tomar en consideración que los primeros modelos de ariete serían muy primitivos, consistiendo únicamente en una viga de madera a la que se había sacado punta para aumentar su capacidad de destrucción. Los soldados la portarían a mano o la balancearían por medio de cuerdas atadas a lo largo de su estructura. Lo primitivo de este ingenio hace que su aparición pueda remontarse al origen de las primeras ciudades, respondiendo a un principio básico. El ser humano necesita romper una puerta y lo primero que se le ocurre es coger un palo y golpearla con él.

Tras esta breve disquisición, dejaré de lado las especulaciones para pasar a las evidencias existentes al respecto de los primeros arietes. Algunos autores consideran que la representación iconográfica del primer ariete aparece en las pinturas murales de algunas tumbas egipcias (Garlan, 1974). A causa de la sencillez de estos diseños iniciales, no es posible confirmar con total seguridad que se trata de ingenios de sitio.

Mayor peso tienen las informaciones que sitúan la invención del ariete en el mundo hurrita. En un texto hitita, cuya cronología podría situarse a mitad del segundo milenio, se alude a la construcción de un ariete a la manera hurrita. Estas reducidas evidencias no ayudan mucho a poder conocer el diseño del arma, pero nos dan unas pautas en relación a su cronología. De nuevo, habremos de regresar a los archivos de Mari, de principios del segundo milenio a. C., para encontrar la referencia al empleo de arietes (yashibum) junto a las torres móviles.

El uso de las primitivas tipologías de arietes de mano resultaba muy peligroso, al quedar los soldados que lo manejaban excesivamente expuestos a los disparos efectuados desde lo alto de las murallas, así como a los materiales arrojados por los defensores. El excesivo riesgo sufrido por sus operarios condujo a que pronto esta máquina quedara dispuesta dentro de otras de mayores dimensiones y más protegidas, como eran las torres de asedio.

Ya se ha insistido abundantemente acerca de la forma en la que se empleaban los arietes dispuestos en el interior de las torres móviles, por lo que no voy a insistir aquí en ese punto. Tan sólo decir que, aunque no es posible apreciarlo en los textos, una vez removidos los adobes de la muralla o rotos, sería necesario recurrir a unidades de zapadores para que retiraran los trozos deteriorados, ayudando a completar la tarea de ruptura de los muros.

Junto a los modelos de ariete ubicados dentro de torres, en el relieve de las puertas de Balawat encontramos un diseño de ariete muy especial. Se trata de una especie de carro pesado desplazado por medio de seis ruedas dotadas de ra- 
dios, dispuestas en tres ejes independientes. Sobre él se disponen unidades de arqueros, que utilizan la máquina como si de una plataforma de disparo se tratara, dedicándose a prestarle fuego de cobertura durante sus maniobras de desplazamiento.

En su parte frontal también se aprecia la presencia de una cabeza afilada, lo que le hace guardar ciertas similitudes con los hocicos de los animales (Sáez Abad, R., 2004: 77). La excepcionalidad de esta imagen, así como su falta de paralelismos, hace que se planteen muchas dudas en relación a su empleo. Casi con total seguridad, se trataría de un modelo móvil en el que no se contaba con una viga independiente que hiciera de movimiento de péndulo, sino que el ariete en sí sería toda la máquina al completo.

\section{EL NACIMIENTO DE LA POLIORCÉTICA: EL ARTE DE ATACAR Y DEFENDER FORTALEZAS}

Tras pasar revista a las técnicas y máquinas de asedio empleadas por los ejércitos neoasirios, se hace necesario ver el marco en el que esos recursos poliorcéticos eran puestos en funcionamiento. Para ello dejaremos de lado las estrategias de asalto por sorpresa y de bloqueo, concentrándonos en el empleo de la táctica de bloqueo activo, por ser precisamente en ella donde se ponían en marcha los principales medios materiales disponibles.

Antes de comenzar, es necesario introducir el siguiente texto, ilustrativo del marco en el que las máquinas de asedio entraban en acción. Relata las operaciones de Senaquerib, durante su campaña contra el reino de Judá:

"Yo asediaba y yo conquisté 46 ciudades fuertes con su muralla y las innumerables pequeñas ciudades de los alrededores por medio de amontonamientos, de rampas y de la proximidad del ariete, del ataque de soldados de infantería, de perforamientos, de brechas y de la utilización de instrumentos de asalto.»

(Luckenbill, D., 1968)

La combinación de estos medios condujo a que la poliorcética dentro del mundo neoasirio se convirtiera en una estrategia estandarizada, en la cual los dirigentes militares seguían unas pautas prefijadas de antemano. El primer paso, tal y como se aprecia en todos los relieves, consistía en la construcción de una rampa de asedio que permitiera el correcto desplazamiento de las máquinas desde las posiciones sitiadoras hasta la base de las murallas. Es necesario tomar en consideración que la arena, principal componente de los suelos mesopotámicos, limitaría mucho la movilidad de los ingenios pesados, que se quedarían atascados en medio de su avance.

De ahí que se requiriera de la construcción de calzadas de arena compactada, en orden a evitar el surgimiento de ese problema. Para evitar que esa arena se desparramara hacia los laterales de la rampa, en algunas de las imágenes se ob- 
serva la presencia de muros de adobe o de piedra en sus laterales, enmarcando perfectamente el camino a seguir por las torres de asedio en su desplazamiento.

Si bien en el mundo grecorromano, para evitar que la tierra de las rampas se desplazara hacia los laterales eran utilizados troncos de árboles, la escasez de este elemento en territorio mesopotámico debió obligar a desestimar su uso, recurriendo a la compartimentación lateral del terreno por medio de adobes. Aunque es imposible apreciarlo en los relieves, también existe la posibilidad de que toda la rampa estuviera surcada en su espacio central por casetones de adobes, destinados a evitar que todo el peso de la rampa recayera sobre los muros laterales.

La construcción de las rampas hacía desaparecer totalmente el factor sorpresa entre las filas defensoras, lo que permitía a la guarnición disponer del tiempo suficiente como para poder replantearse la defensa de la mejor forma posible y articular las estrategias más adecuadas en cada momento. Los relieves neoasirios conservados son un verdadero catálogo de técnicas y tácticas, tanto de ataque como de defensa, preconizando muchas de las estrategias que habrían de resultar claves durante el periodo grecorromano.

Frente a la aproximación de las torres de asedio a los pies de los muros, se observa como los sitiados arrojan sobre ellas toda clase de proyectiles. En primer lugar, y ya desde la distancia, serían lanzadas flechas y piedras por medio de arcos y hondas. Su objetivo, al tratarse de municiones antipersonales, no sería la estructura de la máquina sino los ocupantes que marchaban en su interior y cuya misión consistía en proporcionar fuego de cobertura a los ingenios pesados durante sus movimientos.

Una vez la máquina había alcanzado los pies de la muralla, encontrándose dentro del radio de acción de proyectiles más pesados, los defensores dejarían caer sobre ella objetos de gran calibre. Entre ellos se hallaban piedras pesadas o ruedas de carros, cuya representación resulta especialmente abundante. Algo que no se aprecia con claridad es, si esas ruedas serían arrojadas encendidas, de modo que se incrementara su poder de destrucción.

Lo que sí es posible observar, y en gran número, es el lanzamiento de antorchas sobre la estructura de las máquinas. Ésta era la estrategia de defensa más efectiva contra los ingenios de asedio, en cuya estructura predominaba la madera. Por este motivo, buena parte de los esfuerzos defensivos se concentraban en intentar que las llamas prendieran sobre ellas, siendo éste el único método de lograr su destrucción total.

La realización de salidas por sorpresa, desde el interior de la ciudad objeto de ataque, sería una constante. La ejecución de estos golpes de mano respondía a la necesidad de destruir las máquinas atacantes. En el caso de que las torres móviles estuvieran cubiertas de pieles, como primer paso se hacía necesario arrancarlas, de modo que se quedara expuesta la madera. Sólo de ese modo se garantizaba que el fuego pudiera alcanzar su estructura principal. 
El empleo del resto de técnicas era capaz de inutilizar las máquinas, pero sólo quemándolas se aseguraban que fuera imposible su reparación. La aparición de las pieles sin curtir, como cobertura de la madera, ayudó a mejorar las capacidades ignífugas de las máquinas.

El miedo al fuego era el que conducía a que las torres de asedio, necesariamente debieran contar en su espacio interior con depósitos de agua para responder a cualquier posible contingencia. Revelador de este aspecto resulta uno de los relieves conservados. En él se muestra a los ocupantes de una torre de asedio, dejando caer por medio de una cuchara de grandes dimensiones considerables cantidades de agua sobre la cabeza de un ariete que está golpeando los muros enemigos. No se aprecia si el objetivo del líquido es apagar un fuego ya existente o tan sólo mojar la viga para impedir que puedan prender las llamas (Sáez Abad, R., 2004: 82).

La fragilidad de estas máquinas, de cara a un posible ataque exterior, forzaba a que siempre tuvieran que caminar acompañadas por unidades de infantería, cuya función era protegerlas en todo momento. En este sentido, guardarían ciertas similitudes con los primeros tanques, que necesitaban el apoyo de infantes para evitar ser destruidos por contingentes enemigos.

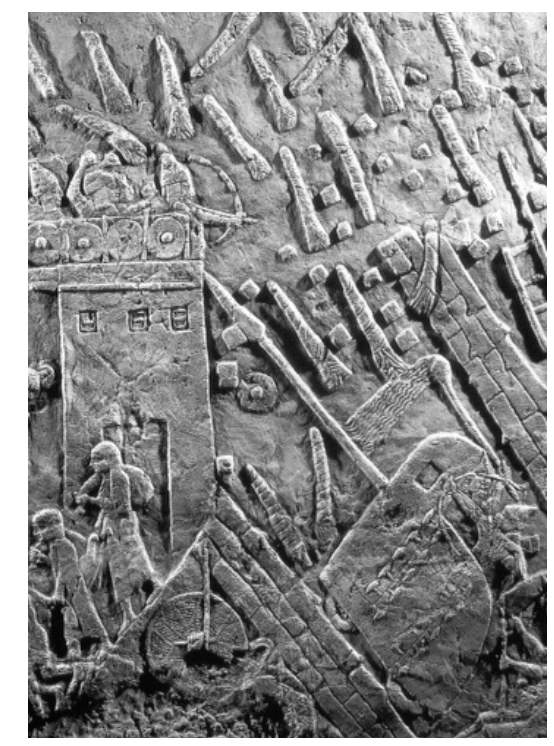

Fig. 6. Asedio de Lakish por medio de torres de asedio en el Palacio de Nínive. British Museum, Londres.

Junto al lanzamiento de proyectiles, de mayor o menor calibre, existían otras muchas técnicas destinadas a frenar el avance destructor de los arietes, algunas de ellas plenas de originalidad. Una de las más interesantes consistía en utilizar 
una cadena para enganchar la cabeza del ariete y levantarla, de modo que se desestabilizara su movimiento, evitando que pudiera golpear los muros. Precisamente, esa técnica la encontramos posteriormente descrita con suma precisión en la obra del autor griego Eneas El Táctico. En un intento por contrarrestar el peso, se aprecia cómo los atacantes tratan de hacer fuerza hacia abajo en dirección contraria con la ayuda de una especie de ganchos, de tal manera que la máquina fuera devuelta a su posición original.

Un punto especialmente vulnerable de las defensas eran las puertas, apreciándose en algunas de las imágenes a los soldados tratando de prenderles fuego. De ahí que, en muchas ocasiones se encontraran revestidas de metal, en orden a evitar que las Ilamas terminaran por destruirlas, permitiendo la entrada de los asaltantes al interior.

Como conclusión, se puede afirmar que los recursos poliorcéticos alcanzaron una enorme complejidad técnica en el mundo neoasirio, siendo el precedente de buena parte de los avances obrados en la Antigüedad en el campo de la guerra de asedio. El Imperio Persa asimiló estos conceptos, exportándose hasta Fenicia, desde donde tomarían diferentes caminos. Por un lado, se desplazaron hacia el Norte con destino a las ciudades griegas de Asia Menor y, en dirección contraria, hacia la floreciente Cartago.

No obstante, a pesar de la enorme ventaja que les proporcionaba a los sitiadores el empleo de las máquinas de asedio, no siempre era suficiente para conseguir la captura de los recintos amurallados. Cuando se trataba de ciudades de grandes dimensiones, que contaban con guarniciones especialmente numerosas, lo más usual era que las estrategias defensivas se impusieran sobre las ofensivas.

Tomando en consideración estos datos, es normal que la captura de buena parte de las ciudades tan sólo pudiera realizarse por medio de la técnica de cerco o bloqueo. Son abundantes los ejemplos de su empleo en territorio mesopotámico. Samaria resistió por espacio de tres años los ataques de los ejércitos neoasirios, antes de caer finalmente el año 721 a. C.

Asaltos por sorpresa, bloqueos o bloqueos activos, eran técnicas muy comunes en el mundo neoasirio. Su combinación con escaleras de mano, minado y zapa de los muros, rampas de asalto, torres móviles o arietes, permitía disponer a los ejércitos sitiadores de abundantes recursos en función de las diferentes necesidades. Esta disponibilidad otorgaba una enorme versatilidad en combate a sus ejércitos, adaptando la estrategia en cada momento al objetivo a batir.

\section{UN ASEDIO EXCEPCIONAL: LAKISH (701 A.C.)}

El asedio de Lakish por parte de los ejércitos neoasirios el año 701 a. C. constituye un excelente ejemplo de cómo las tácticas y máquinas de asedio eran capaces de alcanzar una elevada efectividad en combate. La excepcionalidad de 
este asedio para nuestra investigación reside en el hecho de que, para aproximarnos a él, contamos con muy variadas fuentes, a diferencia de lo que sucede en otros acontecimientos más o menos contemporáneos.

En relación a esta campaña, contamos con abundantes documentos que relatan el desarrollo de los acontecimientos. Por otro lado, se conservan numerosos relieves alusivos a las operaciones de expugnación sobre la plaza, lo cual testimonia de forma fehaciente los medios puestos en escena por los atacantes. A esas representaciones iconográficas, hay que añadir las evidencias halladas durante las excavaciones arqueológicas de la ciudad en cuestión y que ayudan a corroborar lo afirmado por los relieves anteriores. Ni siquiera en época grecorromana, es posible disponer de una combinación semejante de vestigios para ayudar a reconstruir unas operaciones de asedio de esa magnitud.

Según las fuentes escritas, tras subyugar las ciudades de Tiro y Sidón, Senaquerib tomó la decisión de marchar sobre otras ciudades de la región que le pagaban tributo de lealtad. Antes de sufrir la fuerza de las armas, algunas de ellas aceptaron someterse a la autoridad imperial, como Arvad, Asdod, Biblos, Moab, Edom o Judá.

En un intento por evitar el asedio de Jerusalén, Ezequías aceptó pagar el tributo que le fuera impuesto. La petición de Senaquerib ascendió a trescientos talentos de plata y treinta de oro. Ante esta solicitud, el rey de Judá mandó sacar todo el oro que se conservaba en el Templo de Salomón para el pago de los tributos. Incluso fue necesario desguarnecer las puertas del Templo y las jambas, que habían sido recubiertas recientemente de oro (Santa Biblia, Reyes, II, XVIII).

Sin embargo, Senaquerib no se conformó con la cantidad entregada inicialmente y pidió todavía más, algo que resultaba imposible de satisfacer. Para tratar de forzarlo a entregar lo solicitado, el monarca neoasirio marchó contra Jerusalén y su ciudad-fortaleza: Lakish.

Cuando se produjo la confrontación, Lakish era considerada un baluarte poderoso, hasta el punto de ser considerado «la puerta de Jerusalén». Cualquiera que quisiera conquistar la capital de los judíos, necesariamente, debía someter en primer lugar esta plaza de forma previa. De ahí que, su recinto sufriera continuas modificaciones destinadas a adaptarse a los últimos principios poliorcéticos. Las defensas fueron reforzadas durante el reinado de Roboam, junto a otros enclaves próximos, en un intento por crear una línea de fortificaciones que protegiera exteriormente a la capital.

Ni siquiera estas mejoras consiguieron salvar a la ciudad de que fuera tomada. Tras su captura, toda la ciudad quedó desmantelada y desde allí se llevaron 200.000 personas cautivas a Nínive, una cifra que parece ciertamente exagerada. Como ya se ha señalado anteriormente, las deportaciones en masa suponían un castigo común para aquellas poblaciones que optaban por presentar resistencia al poder imperial. Además de los prisioneros, el ejército aprehendió un considerable botín. 
En los relieves conservados es posible apreciar toda la secuencia de las operaciones de conquista. Se observa la presencia de una rampa de asedio, a través de la cual se desplaza una torre de asedio de grandes dimensiones. La máquina va equipada en su parte delantera con un ariete dotado de punta de lanza para facilitar la apertura de brechas. Por detrás de ella caminan numerosas unidades de arqueros, actuando en apoyo de su maniobra de avance. Si hacemos caso a las imágenes presentes en los relieves, al menos serían siete los arietes puestos en marcha contra las murallas de forma simultánea.

En la iconografía es posible ver representado incluso el campamento de asedio en detalle, algo que resulta excepcional. El asentamiento aparece en vista aérea, pudiendo distinguirse desde la altura la forma oval de su muro perimetral. Las capacidades defensivas de esta muralla se ven incrementadas con la presencia de torres defensivas separadas entre sí a diferentes intervalos. El campamento está perfectamente planificado, presentando una calle central que vertebra todo el asentamiento. En él aparecen dos pabellones y cinco tiendas abiertas, hasta apreciarse a los soldados en la realización de sus actividades diarias.

Lo mostrado en los relieves se ha visto corroborado por la información arqueológica. Durante las excavaciones efectuadas en la ciudad a lo largo de los años 30 , se procedió a la exhumación del recinto amurallado que la protegía a lo largo de todo su perímetro. Éste se encontraba reforzado con torres rectangulares cada cierto tramo, cuya misión era mejorar las capacidades defensivas del trazado.

Lo más interesante es el hecho de que, en uno de los extremos de la muralla de la ciudad se aprecia un amontonamiento de bloques de piedra, que constituyen los restos arqueológicos de la primera rampa de asedio de la historia. Esta evidencia resulta excepcional para entender el funcionamiento de las máquinas de asedio, así como la forma en que se efectuaba su despliegue.

Junto a los restos de la rampa mencionada anteriormente, han sido numerosos los proyectiles hallados en el interior de la ciudad. El material encontrado es muy variado, correspondiendo en primer lugar a bolas esféricas de piedra, arrojadas sobre la ciudad por medio de unidades de honderos. También abundan las puntas de flecha, lo que avala la presencia de cuerpos de arqueros junto a las torres móviles. Los hallazgos constatan la enorme concentración de medios materiales y humanos desplegados durante las operaciones de expugnación sobre la plaza y que, tan bien representados, aparecen en los relieves.

Por otro lado, en las excavaciones realizadas por Starkey en 1938 también se encontró una fosa común fuera de la ciudad. En su interior se amontonaban dos mil esqueletos humanos, que habían sido arrojados allí con mucha precipitación, a tenor del modo en que se produjo su descubrimiento. Este espeluznante hallazgo permite corroborar lo afirmado en los textos escritos y en la iconografía. 


\section{BIBLIOGRAFÍA}

A.A.V.V., La Santa Biblia, Editorial Planeta, Barcelona, 1967.

BENTLEY KERN, P., Ancient siege warfare, Indiana University Press, Bloomington and Indianapolis, 1999.

CONTENEAU, G., Everyday Life in Babylon and Assyria, Edward Arnold, London, 1954.

CURTIS, J. E. \& READE, J. E. (Eds), Art and Empire: Treasures from Assyria in the British Museum, Harry N. Abrams, New York, 1995.

DOSSIN, G., Archives Royales de Mari, I, París, 1950.

DUPUY, T. N., The evolution of warfare and weapons, Bobbs-Merrill, New York, 1980

FERRILL, A., The origins of war, Thames and Hudson, London, 1985.

GABRIEL, R. A., The Great Armies of Antiquity, Westport, Connecticut, London, 2002.

GARLAN, Y., Recherches de poliorcetique grecque, París, 1974.

JEAN, CH. F., Archives Royales de Mari, II, París, 1950.

LAFFONT, R., The ancient art of warfare, Time-Life Books, New York, 1966.

LUCKENBILL, D. D., Ancient Records of Assyria and Babylonia, Greenwood Press, New York, 1968.

MADHLOUM, T. A., «Assyrian siege-engines», Sumer, 21, 1965, 9-16.

MITCHELL, T. C., The Bible in the Bristish Museum, The British Museum Press, London, 1988.

MOORTGAT, A., The art of Ancient Mesopotamia, Phaidon, New York, 1969.

OLMSTEAD, A. T., The History of Assyria, University of Chicago Press, Chicago, 1951.

OPPENHEIM, A. L., «Siege-documents» from Nippur, Iraq, XVII, 1955, 69-89.

PARROT, A., Ninive et I Ancient Testament, Delchaux et Niestle, Neuchatel, 1970.

PRITCHARD, J. (Comp.), Ancient Near Eastern Texts relating Old Testament, Princeton, 1955.

ROAF, M., Mesopotamia y el antiguo Oriente Medio, Folio, Barcelona, 1992.

ROAF, M., Cultural Atlas of Mesopotamia and the Ancient Near East, Oxfordshire, Andromeda, 1996.

SÁEZ ABAD, R., La poliorcética en el mundo antiguo, Tesis doctoral, Universidad Complutense de Madrid Servicio de Publicaciones, Madrid, 2004.

SÁEZ ABAD, R., La poliorcética en el mundo grecorromano, C.S.I.C., Anejos de Gladius, vol. 8, Madrid, 2005.

SÁEZ ABAD, R., «El ejército del Imperio Neoasirio: las primeras máquinas de asedio», Espacio, Tiempo y Forma, Serie II, 17-18, UNED, Madrid, 13-33.

SAUVAGE, M. (1991), «Le siege des villes fortifiees», Les Dossier d Archeologie, 160, 5663.

USSISHKIN, D., The conquest of Lachish by Sennacherib, Tel Aviv University, Institute of Archeology, 1982.

WEIDNER, E. F., «Assyrische Beschreibungen der Kriegs-Reliefs Assurbanapalis», Archiv fuer Orienforschung, 8, 175-208.

YADIN, Y., «Hyksos Fortifications and the Battering-Ram», Bulletin of American Schools of Oriental Research, 137, 1955.

YADIN, Y., The Art of Warfare in Biblical Lands in the Light of Archaeological Study, 2 vols., McGraw-Hill, New York, 1960. 